\title{
GAIA Level 3 Assessment of Premature Preterm Rupture of Membranes
}

National Cancer Institute

\section{Source}

National Cancer Institute. GAIA Level 3 Assessment of Premature Preterm Rupture of

Membranes. NCI Thesaurus. Code C127946.

GAIA Level 3 Assessment of Premature Preterm Rupture of Membranes is defined by three criteria: first, presentation between 24 0/7 and 36 6/7 weeks gestation with a clinical history of rupture of membranes, the fluid from which may be any color, including clear, blood-tinged, meconium-tinged (fetal stool), or purulent-tinged (yellowish, suggesting infection); second, the patient is determined to not be in preterm labor (having less than or equal to 4 contractions per hour documented clinically or on tocodynometer, with less than $2 \mathrm{~cm}$ cervical dilation); third, visible leakage of presumed amniotic fluid, which may be on vaginal speculum examination (pooling in the vagina), on inspection of the perineum (wet perineum due to leakage of fluid from the vagina), or fluid soaked cloth/clothes/sanitary pad. 